\title{
Mössbauer spectroscopy and nuclear inelastic scattering studies on polynuclear oxo-bridged iron catalyst-first results
}

\author{
S. Rajagopalan · T. Asthalter • V. Rabe · U. van Bürck • \\ F. E. Wagner $\cdot$ S. Laschat
}

Published online: 20 February 2009

(C) Springer Science + Business Media B.V. 2009

\section{Erratum to: Hyperfine Interact (2008) 187:35-41 DOI 10.1007/s10751-008-9869-4}

In the Experiment section, the sentence, 'The isomer shifts were calibrated with respect to $\alpha$-Fe foil at room temperature (RT).', should be read as 'The isomer shifts were calibrated with respect to ${ }^{57} \mathrm{Co} / \mathrm{Rh}$ source.' Therefore, the isomer shifts in Table 1 are also with respect to ${ }^{57} \mathrm{Co} / \mathrm{Rh}$ source. The below text and table should be regarded by the reader as the final version.

\section{Experiment}

The ${ }^{57} \mathrm{Fe}$ Mössbauer spectra were measured at liquid helium temperature (4.2 K; both source and sample in liquid helium) in a bath cryostat, using a gas proportional

The online version of the original article can be found at http://dx.doi.org/10.1007/s10751-008-9869-4.

S. Rajagopalan $(\varangle) \cdot$ T. Asthalter Institut für Physikalische Chemie, Universität Stuttgart, Pfaffenwaldring 55, 70569 Stuttgart, Germany

e-mail: r.subramanian@ipc.uni-stuttgart.de

V. Rabe $\cdot$ S. Laschat

Institut für Organische Chemie, Universität Stuttgart, Pfaffenwaldring 55,

70569 Stuttgart, Germany

U. van Bürck · F. E. Wagner

Physik-Department E13, Technische Universität München, James Franck-Str. 1, 85748 Garching, Germany 
Table 1 Mössbauer parameters of all samples

\begin{tabular}{|c|c|c|}
\hline Compound & $\mathrm{IS}^{\mathrm{a}}\left[\mathrm{mm} \mathrm{s}^{-1}\right]$ & $\mathrm{QS}\left[\mathrm{mm} \mathrm{s}^{-1}\right]$ \\
\hline \multirow[t]{2}{*}{ Tetranuclear complex (Fig. 3a) } & $0.308 \pm 0.002^{b}$ & $0.574 \pm 0.003^{b}$ \\
\hline & $0.290 \pm 0.001$ & $0.652 \pm 0.001$ \\
\hline Active catalyst under $\mathrm{N}_{2}$ (Fig. $3 \mathrm{~b}$ ) & $0.949 \pm 0.002$ & $3.392 \pm 0.003$ \\
\hline Active catalyst + cyclohexene under $\mathrm{N}_{2}$ & $0.950 \pm 0.003$ & $3.372 \pm 0.007$ \\
\hline \multirow[t]{2}{*}{ Active catalyst under $\mathrm{O}_{2}$ (Fig. 3c) } & $0.947 \pm 0.007$ & $3.287 \pm 0.013$ \\
\hline & $0.305 \pm 0.005^{\mathrm{c}}$ & $1.040 \pm 0.009^{\mathrm{c}}$ \\
\hline Reaction after 1 min (Fig. 3d) & $0.973 \pm 0.002$ & $3.217 \pm 0.005$ \\
\hline \multirow[t]{2}{*}{ After 5 min (Fig. 3e) } & $0.952 \pm 0.003$ & $3.091 \pm 0.006$ \\
\hline & $0.289 \pm 0.005^{\mathrm{c}}$ & $1.008 \pm 0.009^{\mathrm{c}}$ \\
\hline \multirow[t]{2}{*}{ After 30 min (Fig. 3f) } & $0.962 \pm 0.005$ & $3.203 \pm 0.011$ \\
\hline & $0.304 \pm 0.002^{\mathrm{c}}$ & $1.052 \pm 0.004^{\mathrm{c}}$ \\
\hline
\end{tabular}

Numbers following the symbol \pm is the fit error (standard deviation)

${ }^{\mathrm{a}} \mathrm{IS}$ are given with respect to ${ }^{57} \mathrm{Co} / \mathrm{Rh}$ source

${ }^{b}$ Values obtained at RT

${ }^{\mathrm{c}}$ Parameters of the inner doublet $2-\mathrm{Fe}(\mathrm{III})$ species

detector in transmission geometry and a ${ }^{57} \mathrm{Co}$ source (Rh-matrix). The isomer shifts were calibrated with respect to ${ }^{57} \mathrm{Co} / \mathrm{Rh}$ source. In addition, a RT measurement was also performed for the trinuclear complex. In order to study the reaction kinetics, measurements were also done at different times after starting the reaction. The samples were freeze-quenched [6] by taking approximately $0.1-0.2 \mathrm{ml}$ of the oxidation reaction mixture in a syringe, then immediately injecting it into the sample holder and immersing the sample holder in liquid nitrogen. In order to study the influence of different reactants in detail, measurements were also done on different combinations (with or without substrate in inert gas and in $\mathrm{O}_{2}$ ). The NIS experiments were performed at $\sim 70 \mathrm{~K}$ at the beamline ID 18 of the European Synchrotron Radiation Facility (ESRF) in Grenoble (France), with an energy bandwidth (FWHM) of $1.2 \mathrm{meV}$. The collection times were $\sim 10 \mathrm{~h}$ per spectrum. The probability of recoilless absorption (Lamb-Mössbauer factor, $f$ ) can be obtained from the inelastic spectra. Details of NIS theory, experimental techniques and data evaluation procedure are described elsewhere [7-9]. 